\title{
O PAPEL DOS PAIS NA EDUCAÇÃO SEXUAL DA RAPARIGA: UMA ANÁLISE EM FACE DAS RELAÇÕES SOCIAIS DE GÉNERO
}

Joaquim Muchanessa D. Nhampoca*

Abstract: A preocupação com a sexualidade e educação sexual dos filhos é um assunto que faz parte do dia a dia de muitas famílias e sociedades. Foi neste contexto que desenvolvemos este artigo sobre o papel dos pais na educação sexual da rapariga. Uma educação bastante influenciada pelas relações sociais de género e a divisão de papéis na família. Outrossim, destacam-se o processo de socialização primária e os ritos de iniciação que vão perpetuando a construção da imagem e identidade masculina/feminina, orientadora das relações sociais e da conduta do indivíduo.

Palavras-chave: Relações sociais de gênero. Família e educação sexual. 
JOAQUIM MUCHANESSA D. NHAMPOCA 


\section{Introdução}

Gostaria de começar este trabalho duma forma totalmente diferente da habitual ou que caracteriza muitos trabalhos científicos, contando o itinerário de uma viagem que se ajusta ao tema, aqui, tratado.

De regresso de uma viagem de Nampula, uma província nortenha de Moçambique, conheci uma menina dos seus 12 anos de idade, com a qual sentara a bordo do Boeing 737 com destino à Maputo, com uma escala no Aeroporto Internacional da Beira. Após a escala na Beira, já de regresso a bordo, a menina se ofereceu em carregar o meu livro de Sociologia, da autoria de Anthony Giddens. A bordo, eis que a menina começa a folhear o livro, tendo ficado alguns minutinhos observando as imagens de Auguste Comte, Durkheim e Marx. Em tom de brincadeira olhei para ela e disse: "se estudares um pouco mais poderás aprender ou falar destes pensadores".

A curiosidade da menina pelo livro continuou, mas o tema sobre homossexualidade pode ter-lhe criado outra curiosidade ou despertado outra atenção. Não perdendo a oportunidade, fi-la a seguinte pergunta: “já ouviste falar da homossexualidade?". Ao que respondeu dizendo "sim". Aqui começa o meu interesse na elaboração deste artigo sobre "O papel dos pais na educação sexual da rapariga: uma análise em face das relações sociais do género”.

Como objectivos, pretende-se fazer uma análise sociológica sobre o papel dos pais na educação sexual da rapariga, em função das relações sociais de gênero; identificar os factores que definem o papel da mãe e do pai quanto a educação da rapariga; analisar como é que a construção social da imagem masculina e feminina contribui na distribuição de papéis entre homens e mulheres. 


\section{Educação sexual versus relações sociais de género}

As relações sociais de género, como elementos estruturantes, moldam a maneira como um homem e uma mulher se devem comportar na sociedade, sendo por essa via responsáveis pela definição de papéis sociais, consequentemente, a distribuição de papéis quanto a educação dos filhos. Olhamos para o papel social como efetivamente composto por normas a que está submetida a acção dos sujeitos que ocupam uma posição ou uma função particular num grupo ou numa colectividade (Rocher, 1999). Se quisermos, na perspectiva dos factos sociais referidos por Durkheim, estaremos ao nível dos constrangimentos.

Para Traverso-Yépez e Pinheiro (2005), o conceito de género consolidado na expressão relações de género representa a aceitação de que a masculinidade e a feminilidade transcendem a questão da anatomia sexual, remetendo a redes e significação que envolvem diversas dimensões da vida das pessoas.

As relações de género situadas sempre em contextos sociais específicos demarcam espaços, delimitam possibilidades e configuram matrizes ou modelos de interacção entre as pessoas, implicando pressões sobre àquelas que as transgridem ou subvertem (TraveRso-Yépez; Pinheiro, 2005, p. 149).

A educação sexual, sendo o ensino sobre a anatomia e psicologia da reprodução humana, assim como os vários aspectos ligados ao sexo e sexualidade, têm uma forte ligação com as relações de géneros que definem o comportamento dos indivíduos em função do sexo e determinados papéis.

A forma como os pais se comunicam com os filhos, bem como as actividades de que participam com as crianças, tem efeitos po- 
sitivos em toda a situação socioeconómica. Por exemplo, a pobreza durante a infância está fortemente associada a piores resultados no desenvolvimento infantil nos Estados Unidos, mas tal associação parece em parte neutralizada por boas prácticas de cuidados dos pais, como ser carinhoso e receptivo às crianças e proporcionar estímulo para a alfabetização (Minstry et al. [no prelo]; Nichd apud Naudeau et al., 2011, p. 111). As meninas continuam sendo educadas para serem gentis, obedientes, sentimentais, frágeis, delicadas, caseiras, sensíveis, emotivas, prendadas, submissas (Costa, 1986; Fagundes, 2002 apud Ankier, 2004).

Giddens (2000) afirma que estudos sobre a interacção entre mãe e filhos mostram diferenças de tratamento em relação a rapazes e raparigas, mesmo quando os pais acreditam não fazer qualquer discriminação em relação ao género. $O$ comportamento sensível e positivo dos pais e o empenho de ambos aumentam as chances de sucesso académico da criança e ajudam a desenvolver suas habilidades cognitivas e socioemocionais (Naudeau et al., 2011, p. 112). Alguns aspectos do relacionamento pais-filho, em especial a sensibilidade e responsividade da mãe, têm sido associados ao desenvolvimento cognitivo e socioemocional das crianças (Naudeau et al., 2011, p. 112).

Os argumentos de vários autores até aqui apresentados mostram o carácter tendencioso na educação dos filhos, havendo uma preferência quanto ao sexo. Portanto, sendo os pais, vistos aos olhos da sociedade como as pessoas responsáveis pela educação, assistência e protecção dos filhos, como é que devem ou deviam se posicionar em relação à educação sexual da rapariga? 


\section{Metodologia}

Em termos metodológicos, o trabalho baseou-se em entrevistas semiestruturadas, realizadas no terreno, e a revisão de literatura. A estratégia metodológica, usada durante as entrevistas, foi de não apenas envolver os pais, mas também obter o ponto de vista dos filhos, em particular, sobre o papel dos pais na sua educação sexual.

\section{Hipóteses}

a) O papel dos pais na educação sexual da rapariga é feito em função das normas e valores sociais que regem o funcionamento de uma determinada sociedade;

b) A formação acadêmica dos pais, assim como o meio social, influenciam a posição dos pais na educação sexual da rapariga.

\section{Amostra}

O trabalho teve como grupo-alvo mulheres e homens casados, incluindo jovens e adolescentes (na qualidade de filhos), respeitando a faixa etária.

A escolha dos entrevistados foi aleatória mediante sua disponibilidade. Foram entrevistadas seis pessoas, sendo duas mulheres, dois homens e duas crianças (uma rapariga e um rapaz). 


\section{Identidade de género e sexualidade}

A questão de gênero e sexualidade foi amplamente discutida pelas teorias de Freud e Chodorow. Segundo Freud (apud Giddens, 2000), a aprendizagem das diferenças de gênero nos bebés e nas crianças centra-se na posse ou ausência de pénis. A posse ou a ausência do pénis são imagens simbólicas da masculinidade e feminilidade. Chodorow, na citação de Giddens (2000), dá maior ênfase ao papel desempenhado pela mãe, em vez do pai. As crianças têm tendência a ficar ligadas emocionalmente às suas mães, na medida em que elas (as mães) são, sem dúvida, a influência dominante na fase inicial das suas vidas.

Um estudo feito pela Save the children (2011) indica que a saúde, a educação, a nutrição e o bem-estar geral da criança estão muito estreitamente ligados com a mãe. Esta ligação pode muito ter a ver com o tipo de sociedade, se considerar que em Moçambique temos as sociedades matrilineares a norte de Save (nome de um rio) e sociedades patrilineares a sul do Save.

Os rapazes ganham um sentido de individualidade através de uma rejeição mais radical do seu apego primário à mãe, forjando o seu entendimento da masculinidade a partir do que não é feminino. Aprendem a não ser "maricas" ou "meninos da mamã" (Giddens, 2000, p. 130). Vemos, aqui, uma perspectiva social bastante forte quanto a divisão de papéis na educação, não somente sexual, dos filhos. Isto mostra claramente uma oposição à educação formal ou aquela adquirida ao nível das instituições secundárias de socialização. Na escola, por exemplo, as crianças são ensinadas numa perspectiva igualitária sendo todas iguais e possuindo capacidades iguais na apreensão do conhecimento. 


\section{Ritos de iniciação}

Os ritos de iniciação fazem parte de um processo de inculcação e interiorização de valores e normas sociais que contribuem para a construção da identidade masculina ou feminina. Estes ritos, também, determinam a integração e aceitação do indivíduo numa determinada comunidade ou sociedade:

Rito de iniciação refere-se a cerimónia que marca o acesso de um jovem ao estatuto de adulto, em numerosas sociedades primitivas. De modo mais geral, acto solene pelo qual um indivíduo é introduzido como membro de um grupo (confraria, sociedade secreta). (DICIONÁRIO DE ECONOMIA E CIÊNCIAS SOCIAIS, 2001, p. 208).

Quando se chega a grande, o rapaz abandona o rebanho de cabras e confiam-lhe a guarda do gado graúdo: bois e vacas, se o pai os possui. Torna-se muito orgulhoso e tiraniza os irmãos mais novos; dá a si próprio o nome de 'hosi', chefe, fá-los trabalhar por conta própria. No Maputo, os rapazes crescidos chegavam até a desdenhar da água que as mulheres tinham trazido do lago e só, queriam servir-se da água trazida muito especialmente para eles pelos mais pequenos. Se adquiriram a seus próprios olhos uma tal importância, é porque foram submetidos, durante este período, a ritos especiais... alguns destes ritos dizem directamente respeito à vida sexual, outros representam somente a sua entrada na idade viril. (JUNOD, 1996, p. 85).

Podemos dizer, assim como Andràs Zempléni, que o protótipo dos ritos de passagem são os ritos de iniciação: como os ritos de passagem, os ritos de iniciação marcam a transição de um status social para outro (morte e renascimento simbólicos). A iniciação é, portanto, a 'forma sintética dos ritos de passagem, por meio dos quais ela opera'. Mas a iniciação é mais do que simplesmente um rito de transição, ela é um rito de formação. (RODOLPHO, 2004, p. 143-144).

A práctica de ritos de iniciação, em Moçambique, varia de região para região, do norte ao sul do país, mas mantendo sua 
função manifesta e dimensão simbólica. Aliás, encontramos em Moçambique dois tipos de sociedades: sociedades matrilineares ${ }^{2}$ e sociedades patrilineares ${ }^{3}$; sendo a primeira a norte do Save e a segunda a sul do Save.

Como ilustram os extractos acima, os ritos de iniciação não contribuem, apenas, para a integração do indivíduo, num grupo, comunidade ou sociedade, mas também estruturam as relações sociais que este indivíduo vai (ou passa a) estabelecer com os outros. Aqui, há relações de dominação, de masculinidade, de autoridade e de superioridade, o que coloca em si a posição da rapariga (mulher) na estrutura social e da organização. Em última estância, a diferenciação nos ritos e tipo de educação dada aos rapazes e raparigas.

\section{A Família, sexualidade e os desafios na Educação dos filhos}

A família constitui um grupo em que se estabelecem relações de parentesco entre os seus membros, isto é, relações baseadas em laços de sangue e de casamento (Oliveira et al., 1990, p. 253). Ela é a principal instituição por meio da qual a sociedade regula a satisfação das necessidades sexuais e organiza a procriação (Oliveira et al., 1990, p. 258).

A Constituição da República de MoçamBIQUE (CRM), NO SEU ARTIGO 119 (SOBRE A FAMÍLIA), CONSIDERA:

1. A família é o elemento fundamental e a base de toda a sociedade;

2. O Estado reconhece e protege, nos termos da lei, o casamento como instituição que garante a prossecução dos objectivos da família; 
3. No quadro do desenvolvimento de relações sociais assentes no respeito pela dignidade da pessoa humana, o Estado consagra o princípio de que o casamento se baseia no livre consentimento;

4. A lei estabelece as formas de valorização do casamento tradicional e religioso, define os requisitos do seu registo e fixa os seus efeitos.

\section{Com relação à maternidade e paternidade (artigo 120), a}

\section{Constituição refere-se ao seguinte:}

1. A maternidade e a paternidade são dignificadas e protegidas;

2. A família é responsável pelo crescimento harmonioso da criança e educa as novas gerações nos valores morais, éticos e sociais;

3. A família e o Estado asseguram a educação da criança, formando-a nos valores da unidade nacional, no amor à pátria, igualdade entre homens e mulheres, respeito e solidariedade social;

4. Os pais e as mães devem prestar assistência aos filhos nascidos dentro e fora do casamento.

No Artigo 121, referente à Infância, a Constituição estabelece:

1. Todas as crianças têm direito a protecção da família, da sociedade e do Estado, tendo em vista o seu desenvolvimento integral;

2. As crianças, particularmente as órfãs, portadoras de deficiência e as abandonadas, têm protecção da família, da socie- 
dade e do Estado contra qualquer forma de discriminação, de maus tratos e contra o exercício abusivo da autoridade na família e nas demais instituições.

Se olharmos atentamente para o conteúdo constante dos Artigo 119, 120 e 121, da CRM, notamos que há uma tendência de definir a família e atribuir responsabilidades na perspectiva organicista e funcionalista. Aqui a família é vista como um organismo vivo e como um sistema, visando responder as diversas funções garantindo o equilíbrio e o consenso. Portanto, a educação sexual será, e é, parte integrante das funções da família.

A família, como instituição, responde pela socialização primária dos filhos, sendo a base da construção da identidade e personalidade da criança. Todavia, a mudança de papéis, a dinâmica e mobiliidade social, verificadas nas sociedades actuais, faz com que os pais releguem a educação dos filhos a outras instituições como a escola:

Existe, em quase todas as sociedades, uma tendência para que certos aspectos da educação das crianças sejam assumidos por agentes externos à família, tais como escolas e grupos de iniciação. Mas o grau de dependência física das crianças pequenas em relação às mães estabelece um limite de idade abaixo do qual estes agentes não podem operar. (OLIVEIRA et al., 1990, p. 253).

Cabe aos pais, ou outras pessoas encarregadas, a responsabilidade primordial de proporcionar; de acordo com suas possibilidades e meios financeiros, as condições de vida necessárias ao desenvolvimento da criança. (CDC, art 27) $)^{4}$ 
As múltiplas formas de viver em família, e os diversos modelos de família que actualmente coexistem em todas as sociedades, embora com importantes diferenças relacionadas com cultura e tradição, reflectem também diferentes fases de domínio da natureza e avanços ou recuos na ciência e na tecnologia (Vicente, 1999, p. 31). O acesso das raparigas à educação é considerado, nas novas perspectivas de desenvolvimento humano e sustentado, como o investimento mais rentável que qualquer governo pode fazer, é a medida política mais eficaz para melhorar a qualidade de vida das populações adultas e dos seus filhos (Vicente, 1999, p. 43). Esta ideia pode ser sustentada pelo artigo 29 da Convenção dos Direitos da Criança, relativa a educação da criança.

\section{Análise e discussão dos resultados}

O trabalho de campo e a análise do conteúdo das entrevistas mostram que há uma responsabilização, por parte de alguns pais, às mães quanto a educação, não apenas sexual, da rapariga. Esta responsabilização pode até certo ponto ser influenciada, por um lado, pelas mães que consideram ser anormal um pai desenvolver conversas ligadas a sexualidade com a filha (como resultado de todo um conjunto de tabus e construtos sobre papéis masculinos e femininos). Por outro lado, pelo facto de certos pais considerarem a questão da maternidade e o factor sexo igual, fundamental para encarregar a mulher na educação (sexual) da rapariga.

Esta visão socialmente legitimada entra em contraste com os designíos da Lei da Família (Lei 10/2004), se não vejamos: 
O disposto no número 1 do Artigo 290 da Lei da Família mostra que 'cabe a ambos os pais, de acordo com as suas possibilidades e com o superior interesse dos filhos, promover o desenvolvimento físico, intelectual e moral daqueles. O artigo 291 da mesma Lei destaca o 'dever dos pais de transmitir os valores éticos, morais, familiares, culturais e estruturantes de uma personalidade equilibrada e tolerante no respeito pela família e pelos mais velhos'.

A questão da sexualidade é com frequência reduzida, pelos jovens, ao acto sexual ou então ao coito. Esta maneira de tratar o assunto, no nosso entender, pode contribuir para o distanciamento na comunicação entre jovens e pessoas adultas em questões de sexualidade, em face dos tabus:

A sexualidade continua ainda para muitas/os jovens e adultos apenas questões relacionadas com o acto sexual, as conseqüências que daí decorrem (ITS, gravidez). Persistem também constrangimentos em termos de comunicação entre os mais velhos e os mais novos, dada a forma como o tratamento destas questões aparece sempre encoberto por véu onde se escondem os tabus e medos... (CHANCHA; NYANGA apud SILVA et al., 2007).

O fechamento entre pais e filhos, em especial pai/filha no tratamento de assuntos sexuais como as infecções de transmissão sexual (ITS), a gravidez precoce, o comportamento sexual em face do HIV/ SIDA, entre outros, parece ser movido por uma tendência ou impulso natural que deposita uma maior confiança à mãe. Aqui, merece atenção o papel desempenhado pelas instituições que lidam com a questão da Saúde Sexual e Reprodutiva. Na promoção da saúde sexual não se pode perder de vista o facto de que, em muitas sociedades, homens e mulheres não poderem ter o mesmo acesso ao poder. Crenças, socialmente construídas, estruturam e privilegiam o poder masculino em face das mulheres (Mitchell, 2004, p. 211). 
As normas e os valores sociais, nas comunidades, têm um peso quanto à educação da rapariga. Isto ocorre devido aos constrangimentos sociais e a construção social em torno do papel desempenhado pelo pai e pela mãe na educação sexual da rapariga. Considerando o relativismo dos valores e normas sociais, variando de contexto para contexto, podemos aferir que a educação sexual da rapariga não apenas depende dos pais, mas também dos imperativos sociais da sociedade:

Encontramos distorções provocadas pela falta de informações que passam de pais para filhos levando o adolescente a percorrer caminhos penosos, quando em seu lugar poderia ter gratas alegrias e uma vida mais sadia. (COSTA, 1986 apud ANKIER, 2004).

Os pais sabem explicar os assuntos relacionados a sexo, transmitem falsos conceitos, não debatem com os filhos sobre suas angústias porque eles não sabem lidar com suas próprias. (MONESI; RODRIGUES JR., 1986 apud ANKIER, 2004).

Numa negação dos direitos sexuais dos jovens, a noção espalhada entre os pais é de que eles não devem aceder à informação sobre a sexualidade, contraceptivos e outros serviços, porque não são tidos como seres sexuais. Afirmam que, os esforços para os tornar acessíveis poderão conduzir à promiscuidade e aumentar a sua vulnerabilidade. Líderes de opinião e pais não são as pessoas com quem se discute normalmente os assuntos relacionados com o comportamento sexual, embora os mesmos estejam ostensivamente no âmbito das preocupações familiares: os implicados sentem-se mais à vontade para procurar confidentes fora do grupo familiar. (AGADJANIAN apud LOFORTE, 2006).

A formação acadêmica dos pais e o meio social não influenciam necessariamente na posição dos pais quanto a educação sexual da rapariga. Mais uma vez voltamos ao poder da consciência colectiva em face da consciência individual. Isto é, na perspectiva durkheimiana, as maneiras de agir, pensar, ser e estar, comuns à sociedade, exercem um poder coercitivo sobre os indivíduos. 


\section{Conclusão}

A educação sexual da rapariga na nossa sociedade ainda é um assunto carregado de tabus. As mães assumem que os pais intervêm na educação sexual da rapariga, contudo, esta posição é apenas aparente, pois elas têm sido as pessoas encarregues pelos maridos para desempenhar este papel alegando ser assunto de mulheres.

O comportamento dos pais em face da questão da sexualidade acaba influenciando o comportamento dos filhos. Isto leva a que as raparigas confiem mais na mãe do que no pai, acontecendo o mesmo com o rapaz que deposita sua confiança no pai, mas, muitas vezes, não em questões de sexualidade.

As relações sociais de género, o papel social, assim como as expectativas de papel, jogam seu papel em todo o processo de educação dos filhos, começando pelo próprio processo de socialização primária. Aqui é importante referir-se ao afecto que as mães têm com os bebés, o que contribui na confiança que os filhos depositam na mãe.

\section{Referências}

ANKIER, Cila. Educação sexual do filho e da filha. Arquivos H. Ellis, v. 1, n. 1, p. 27-31, 2004.

CONSTITUIÇÃO DA REPÚBLICA DE MOÇAMBIQUE. Maputo: Imprensa Nacional de Moçambique, 2004.

CONVENÇÃO DOS DIREITOS DA CRIANÇA. Genebra, 1989.

GIDDENS, Anthony. Sociologia. 2. ed. Lisboa: Fundação Calouste Gulbenkian, 2000. 
JUNOD, Henri A. Usos e Costumes dos Bantu. Maputo: ArquivoHistórico de Moçambique, 1996. (Tomo I, Documentos 3).

LEI N¹0/2004 DE 25 DE AGOSTO, LEI DA FAMÍlIA. Maputo: Imprensa Nacional, 2004.

LOFORTE, Ana Maria. Noções de Sexualidade: respondendo às necessidades dos jovens em matéria de saúde sexual e reprodutiva. Outras Vozes, n. 19, maio 2006.

MITCHELL, Anne. Sexual health. In: MOODIE, Rob; HULME, Alana (Eds.). Hands-on Health promotion. Melbourne: IP Communications, 2004. p. 207-217.

NAUDEAU, Sophie et al. Como investir na Primeira Infância: um guia para a Discussão de Políticas e a Preparação de Projectos de Desenvolvimento da Primeira Infância. São Paulo: The World Bank; Singular, 2011.

OLIVEIRA, Maria da Luz. Sociologia. 5. ed. Lisboa: Texto Editora, 1990.

OSÓRIO, Conceição. Sociedade matrilinear em Nampula: estamos a falar do passado? Outras Vozes, n. 16, ago. 2006.

ROCHER, Guy. Sociologia Geral, Acção Social. 6. ed. Lisboa: Editorial Presença, 1999.

RODOLPHO, Adriane Luísa. Rituais, ritos de passagem e de iniciação: uma revisão da bibliografia antropológica. Estudos Teológicos, v. 44, n. 2, p. 138-146, 2004.

SAVE THE CHILDREN. Vidas Curtas: sobrevivência e desenvolvimento da criança em Moçambique, Maputo: Unicef, 2011.

SILVA, Teresa Cruz et al. Representações e práticas da sexualidade dos jovens e a feminização do SIDA em Moçambique. Maputo: Relatório de Pesquisa, WLSA Moçambique, 2007. 
TRAVERSO-YÉPEZ, Martha A.; PINHEIRO, Verónica de Sousa. Socialização de Gênero e Adolescência. Estudos Feministas, Florianópolis, v. 13, n. 1, jan./abr. 2005.

VICENTE, Ana. Direitos das mulheres, Direitos humanos, Publicações do Projecto RAF/97/PO7. Lisboa: Ministério da Saúde, 1999.

\section{Notas}

* Professor da Universidade Educardo Mondlane, Departamento de Sociologia, Moçambique.

${ }^{1}$ Neste tipo de sociedade os filhos pertencem a mulher, o apelido, a herança e a sua educação é relegada à mãe e às tias maternas. Como afirma Osório (2006), exime os homens de quaisquer deveres (mesmo ao nível do simbólico) em face das crianças.

${ }^{2}$ São baseadas em sistemas em que os homens detêm do maior poder financeiro e político; em termos sociais, os homens são chefes de família, a eles pertencem os filhos. O nome da família resulta do apelido do homem e as relações sociais assentam na dominação masculina.

${ }^{3} \mathrm{~N}^{\circ} 2$ do Artigo 27 da Convenção dos Direitos da Criança (CDC). 
